\title{
A Scalable Screening of E. coli Strains for Recombinant Protein Expression
}

\author{
Luana G. Morão ađl, Lívia R. Manzine ${ }^{\mathrm{aql}}$, Angélica Luana C. Barra ${ }^{\mathrm{a}, \mathrm{b}}$, Lívia Oliveira D. \\ Clementino $^{a}$, Raíssa F. Gutierrez ${ }^{\mathrm{a}}$, Carsten Wrenger ${ }^{\mathrm{c}}$ and Alessandro S. Nascimento ${ }^{\mathrm{a} *}$.
}

a. Pólo TerRa, São Carlos Institute of Physics, University of São Paulo. Av. João Dagnone, 1100, Jd. Santa Angelina, 13563-120. São Carlos, SP. Brazil.

b. Institute of Biochemistry and Molecular Biology, Laboratory for Structural Biology of Infection and Inflammation, University of Hamburg, c/o DESY, Build. 22a. Notkestr. 85, 22603 Hamburg, Germany.

c. Unit for Drug Discovery, Department of Parasitology, Institute of Biomedical Sciences, University of São Paulo, Av. Prof. Lineu Prestes 1374, 05508-000 São Paulo-SP, Brazil. II These authors contributed equally to this work.

* Corresponding author: Phone: +55-16-3373-8709. Email: asnascimento@ifsc.usp.br. 


\begin{abstract}
Structural biology projects are highly dependent on the large-scale expression of soluble protein and, for this purpose, heterologous expression using bacteria or yeast as host systems are usually employed. In this scenario, some of the parameters to be optimized include $(i)$ those related to the protein construct, such as the use of a fusion protein, the choice for an $\mathrm{N}$-terminus fusion/tag or a C-terminus fusion/tag; (ii) those related to the expression stage, such as the concentration and selection of inducer agent and temperature expression and (iii) the choice of the host system, which includes the selection of a prokaryotic or eukaryotic cell and the adoption of a strain. The optimization of some of the parameters related to protein expression, stage (ii), is straightforward. On the other hand, the determination of the most suitable parameters related to protein construction requires a new cycle of gene cloning, while the optimization of the host cell is less straightforward. Here, we evaluated a scalable approach for the screening of host cells for protein expression in a structural biology pipeline. We evaluated six Escherichia coli strains looking for the best yield in soluble protein expression using the same strategy for protein construction and gene cloning. For the genes used in this experiment, the Arctic Express (DE3) strain resulted in better yields of soluble proteins. We propose that screening of host cell/strain is feasible, even for smaller laboratories and the experiment as proposed can easily be scalable to a high-throughput approach.
\end{abstract}

Keywords: Recombinant protein expression, E. coli strains, scalable protein expression. 


\section{Introduction}

Many drug discovery projects rely on the structure determination of the drug targets. Indeed, to the best of our knowledge, the so-called 'structure-based rational design' of drug candidates dates to 1976, a year before the Protein Data Bank (PDB) was founded, when Beddell and coworkers designed a series of compounds to fit the human haemoglobin site [1]. Typical structural biology pipelines require pure and soluble protein in high amounts, which is usually achieved by heterologous expression in E. coli [2,3] or in yeast cells, such as Pichia pastoris or Saccharomyces cerevisae, or even in fungus, such as Aspergillus niger (e.g., [4]).

E. coli is the host cell of choice in structural biology approaches, due to the ease in handling, rapid doubling time, and very well-established protocols for expression. In our own group experience, protein expression in E. coli for high-throughput (HT) pipelines resulted in yields up to $946 \mathrm{mg}$ of protein expressed per liter of culture, with an average of about $60-70 \mathrm{mg} . \mathrm{L}^{-1}$ for enzymes of the glycoside hydrolase family [5]. Although this pipeline works very well for most cases, some 'difficult cases' require additional efforts, that include new cloning strategies, such as the addition of fusion tags or even change of tags from $\mathrm{C}$-terminus to $\mathrm{N}$-terminus and vice versa [6]; the exchange of expression vector, suiting of the expression protocol or replacing the host cell.

In this context, several HT strategies have been developed for parallel cloning of genes of interest in different constructions, which explore different fusion proteins, different tags, and the location of the tag [6-8]. Also, protocols for increasing the yield of soluble expression of target proteins are now abundant in the literature (e.g., [3]). Finally, a myriad of commercial E. coli strains is available for efficient heterologous protein expression, promising high yield and enhanced solubility, especially for insoluble protein, making the choice for a particular strain a non-straightforward task.

Here we show the results for a scalable parallel screen for the expression of difficult cases using four different strains. The assay can be readily scalable for an HT format and also include more strains. We show that the screening for expression efficiency in different strains can be a feasible and rapid way to rescue target genes that failed to be soluble expressed in the first HT approach, avoiding going back to the cloning stage of the structural biology pipeline. 


\section{Materials and methods}

All the genes tested in this work were cloned in the pETTRXA-1a/LIC using the strategy previously described by Camilo \& Polikarpov [5]. Besides, for a particular target (target T16) the pET-NESG vector was used. The pET-Trx1A-LIC is a ligation independent cloning-based vector where the target gene is expressed with an $\mathrm{N}$-terminal His-tag fused to thioredoxin and a cleavage site for the Tobacco Etch Virus (TEV) protease.

\subsection{Gene Cloning}

The LIC cloning protocol using pETTRXA-1a/LIC vector was performed as described previously [5]. Briefly, the plasmid was linearized by PCR using the following oligonucleotides: Fw- 5' $5^{\prime}$ TGGCGCCCTGAAAATAAAG; Rv5'CCGCGTCGGGTCAC and, for targets, genomic DNAs were used as templates in PCR amplification using Phusion High-fidelity DNA Polymerase (New England Biolabs). PCR products were individually treated for $16 \mathrm{~h}$ at $37^{\circ} \mathrm{C}$ with 20 units of DpnI enzyme (New England Biolabs). Following gel extraction using Wizard SV Gel and PCR CleanUp System (Promega), $500 \mathrm{ng}$ of purified and linearized vector and $200 \mathrm{ng}$ of each specific gene were treated with T4 DNA polymerase enzyme (Fermentas) in the presence of $2.5 \mathrm{mM}$ dTTP (vector) and $2.5 \mathrm{mM}$ dATP (gene) for $30 \mathrm{~min}$ at $22{ }^{\circ} \mathrm{C}$. Annealing of LIC vectors and insert was performed after incubation of $3 \mu \mathrm{L}$ of T4 Polymerase-treated PCR fragments with $1 \mu \mathrm{L}$ of T4 Polymerase-treated vector at $25^{\circ} \mathrm{C}$ for $30 \mathrm{~min}$. Then, the mixture was used for E. coli DH5 $\alpha$ competent cells transformation and positive clone selection achieved in culture plates containing LB agar medium with $50 \mu \mathrm{g} \mathrm{mL} \mathrm{m}^{-1}$ kanamycin after overnight incubation at $37^{\circ} \mathrm{C}$. 


\subsection{Protein Expression}

Sixteen target genes were cloned following the procedures above. The resulting vectors were used for $E$. coli expression in five DE3 strains: Lemo21, BL21, pT-GroE, Rosetta-gami 2, and Arctic Express. Transformations were performed in 24-well-LB-agar plates containing: kanamycin $(50 \mu \mathrm{g} \mathrm{mL}-1)$ and chloramphenicol $\left(34 \mathrm{ug} \mathrm{mL}^{-1}\right)$ for Lemo21, pTGroE, and Rosetta-gami 2 cells; kanamycin $\left(50 \mu \mathrm{g} \mathrm{mL}^{-1}\right)$ and gentamycin $\left(20 \mu \mathrm{g} \mathrm{mL}^{-1}\right)$ for Arctic Express. Colonies were inoculated in DW96 preculture plates containing $1 \mathrm{~mL}$ of LB medium supplied with cells specific antibiotics, sealed, and incubated overnight at $37{ }^{\circ} \mathrm{C}$ with shaking. Then, $100 \mu \mathrm{L}$ of preculture was inoculated in 5 DW24 plates containing $4 \mathrm{~mL}$ of LB with specific antibiotics (plus $0.5 \mathrm{mM}$ rhamnose for Lemo2 1 cells) and grown at $37{ }^{\circ} \mathrm{C}$ under $150 \mathrm{rpm}$ agitation during $5 \mathrm{~h}$. Afterward, aliquots were collected and IPTG induction was performed using $0.4 \mathrm{mM}$ final concentration for Lemo 21 and $1 \mathrm{mM}$ for the other strains. The temperature was reduced to $18{ }^{\circ} \mathrm{C}$ (pTGroE and Rosetta-Gami 2), $30{ }^{\circ} \mathrm{C}$ (Lemo21), or $11{ }^{\circ} \mathrm{C}$ (Arctic Express), and expression was conducted for $16 \mathrm{~h}$ at $150 \mathrm{rpm}$. In parallel, $100 \mu \mathrm{L}$ of pre-culture was inoculated in 5 DW24 plates containing $4 \mathrm{~mL}$ of ZYP5052 [9] auto-induction medium, and the expression was performed as LB-conditions without IPTG. The plates were centrifuged for $10 \mathrm{~min}$ at $2000 \mathrm{xg}$ and each pellet was resuspended with $1 \mathrm{~mL}$ of lysis buffer (Tris-HCl $50 \mathrm{mM}, \mathrm{NaCl} 300 \mathrm{mM}$, lysozyme $0.25 \mathrm{mg} \mathrm{mL}^{-1}, 0.1 \mathrm{mM} \mathrm{PMSF}$, at pH 8). Cells were lysed by freezing at $-80{ }^{\circ} \mathrm{C}$ overnight and thawing at $17{ }^{\circ} \mathrm{C}$ for $1 \mathrm{~h}$ under agitation. DNAseI (Sigma) was added at $10 \mu \mathrm{g} \mathrm{mL} \mathrm{m}^{-1}$ final concentration following incubation at $17^{\circ} \mathrm{C}$ for $15 \mathrm{~min}$. The lysate purification was carried out in an automated platform Freedom EVO 200 (Tecan) using Ni-Sepharose 6 Fast Flow Resin (GE) in 96well Receiver Plates $20 \mu \mathrm{m}$ (Macherey-Nagel). The lysate passed through the resin by vacuum filtration followed by resin washing with $1 \mathrm{~mL}$ of buffer A (Tris-HCl $50 \mathrm{mM}$, $\mathrm{NaCl} 300 \mathrm{mM}, \mathrm{pH}$ 8) and buffer B (Tris-HCl 50 mM, NaCl $300 \mathrm{mM}$, imidazole $20 \mathrm{mM}$, $\mathrm{pH} 8$ ) for removal of unspecific and unbounded proteins. Elution of interest proteins was performed with $150 \mu \mathrm{L}$ of buffer $\mathrm{C}$ (Tris- $\mathrm{HCl} 50 \mathrm{mM}, \mathrm{NaCl} 300 \mathrm{mM}$, imidazole $300 \mathrm{mM}$, $\mathrm{pH} 8$ ) and samples were analyzed by gel electrophoresis for expression protein screening evaluation. The expression yield of the soluble proteins expressed was assessed by Coomassie-stained SDS-PAGE $15 \%$. 


\section{Results}

Sixteen 'difficult cases' genes were identified in our typical protein expression pipeline. In this pipeline, the genes are cloned in the pETTRXA-1a/LIC vector and expressed in E. coli Rosetta 2 (DE3) strain. In 13 out of the 16 cases, no soluble protein expression could be observed, or the expression yield was very low for a structural biology pipeline. These targets include bacterial (Staphylococcus aureus and Enterococcus faecalis, Mycobacterium tuberculosis) enzymes, as well as plasmodial enzymes (Plasmodium falciparum and Plasmodium vivax). The genes were initially synthesized with codon optimization for E. coli expression. The only exception was the E. faecalis genes, in which the genes were cloned directly from the genomic DNA. All the constructs present a molecular weight among 30-50 kDa and some of them are underrepresented in the PDB, suggesting that they are difficult cases for protein expression in the structural biology pipeline in general. A summary of the genes selected for the screening of soluble expression in E. coli strains is shown in Table 1.

The protein purification procedures, as described in the Materials and Methods section, are assisted by liquid-handling robots, making it very easy to scale the assay for an HT format by increasing the number of targets or the number of strains tested. The procedure followed the same HT strategy previously established [5]. The actual bottleneck was the protein expression since every E. coli strain has its typical resistance marker and its optimal temperature for expression. In our assay, the growing temperature was set to $37{ }^{\circ} \mathrm{C}$ for all strains and different temperatures were used in the induction stage, by allocating each strain in a different shaker. Although this step requires some human effort, it is easily scalable to include more strains, in particular, if the additional strains can be used in the same expression temperatures, or even for more genes, since they can be used in the same plate in each shaker. After the protein expression step, the samples were collected in a single plate for the purification procedure. The process can be further optimized for an HT format, but it becomes clear that the current format is readily scalable for additional genes/strains.

After purification, the obtained expression levels were compared by SDS-PAGE analysis. Figure 1 shows the electrophoresis analysis obtained for the expression of the target genes and the results are also summarized in Table 2. Targets T1, T2 and T7 are orthologous enzymes from E. faecalis, S. aureus, and P. falciparum, respectively, and 
bioRxiv preprint doi: https://doi.org/10.1101/2021.03.09.434560; this version posted March 15,2021 . The copyright holder for this preprint (which was not certified by peer review) is the author/funder, who has granted bioRxiv a license to display the preprint in perpetuity. It is made available under aCC-BY-ND 4.0 International license.

all of them showed negligible soluble expression in E. coli Rosetta 2 strain. When tested for the expression in Rosetta Gami 2, pT-GroE, LEMO21, and Arctic Express, we observed soluble recovery of T1 in Rosetta Gami 2, pT-GroE, Lemo21, and Arctic Express. Additionally, T2 was recovered in minimal amounts in Rosetta Gami 2 and Arctic Express, while T7 was recovered in higher amounts in Arctic Express and small amounts in the other strains tested.
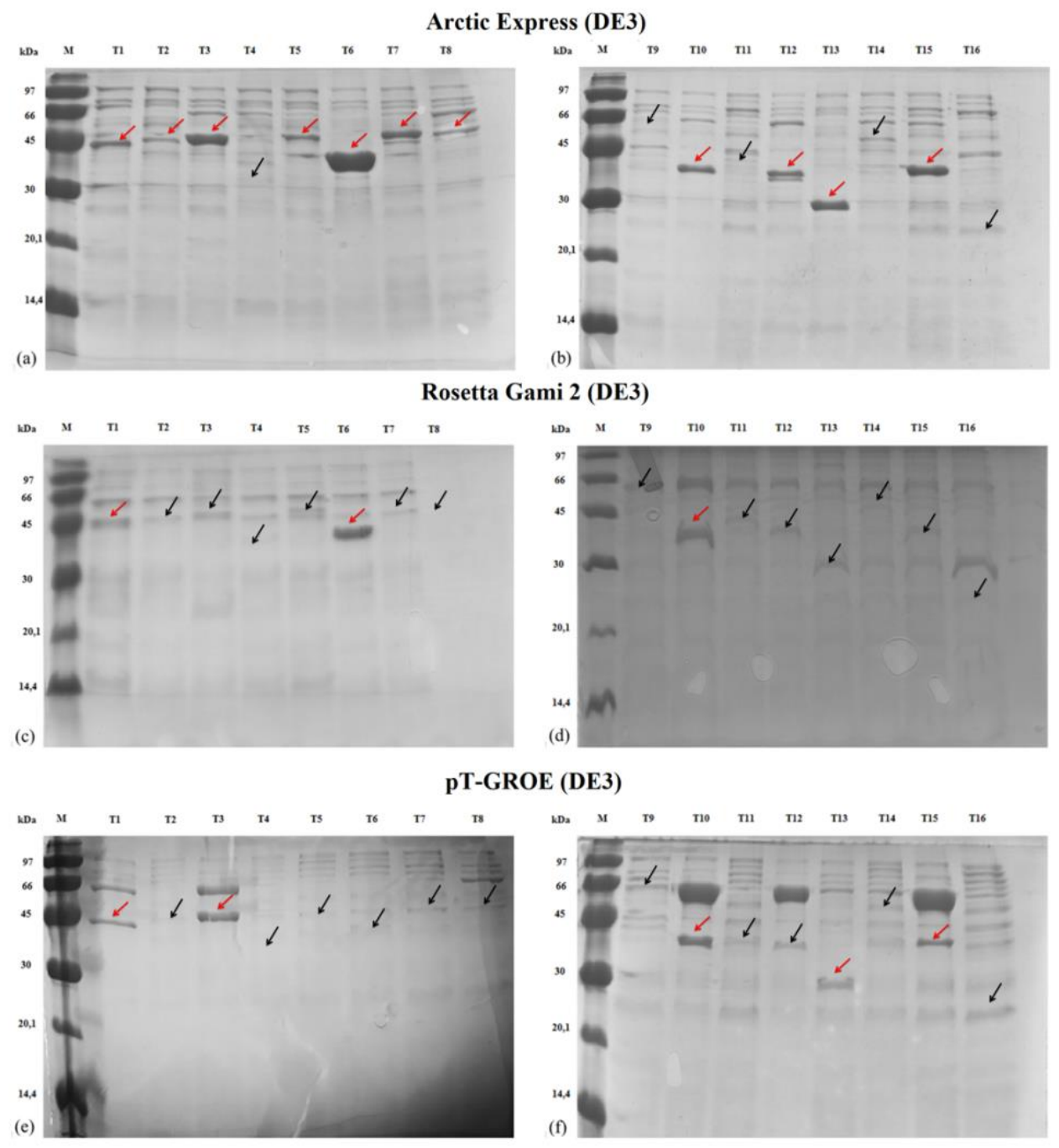

Lemo 21 (DE3)
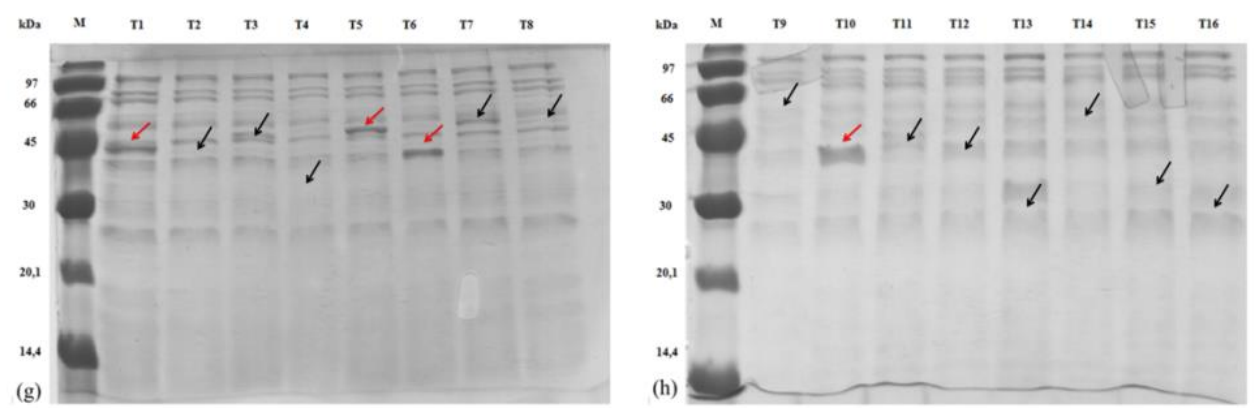

Figure 1. SDS-PAGE (15\%) analysis of soluble protein recovery in the four strains used in this work. The red arrows indicate the recovered protein with the correct molecular weight. The black arrows indicate the molecular weight of the proteins that were not recovered or only minimally recovered. 
The targets T3, T4, T5, T6, and T10 are five enzymes of the same pathway in $M$. tuberculosis and Plasmodium species. Out of these five targets, the Arctic strain recovered three of them in the soluble form and a fourth target (T5) to a lesser extent, while pT-GroE recovered two of them with a very good expression pattern (T3 and T10). Lemo21 strain recovered T5, T6, and T10, and Rosetta Gami 2 recovered targets T6 and T10. The targets $\mathbf{T 8}$ and $\mathbf{T 9}$ were recovered in very low yields in the pT-GroE strain. The Arctic Express strain also recovered slow amounts of T8, while Rosetta Gami 2 recovered small amounts of $\mathbf{T 9}$.

The targets T11 and T14 are glycosyltransferases, which are targets known to be insoluble in many cases. T11 was also tested for its expression in two truncated forms (T12 and T13) and also in the full-length protein in the pET-NESG vector (T16). A truncated form of $\mathbf{T 1 4}$ was also tested in the pETTRXA-1a/LIC vector and is listed as T15. The Lemo21 strain was not able to recover any of the targets, while Rosetta Gami recovered only $\mathbf{T 1 3}$ to a very small extent. The pT-GroE strain recovered two of the truncated forms for these targets (T13 and T15) and, to a lesser extent, the third truncated form (T12). Finally, the Arctic strain recovered the same three truncated forms with very good contrast to the background proteins observed in the SDS-PAGE.

\section{Discussion}

After screening the strains available in our group, we found, in general, that 9 out of the 16 targets, or $56 \%$ were recovered in reasonable amounts. In at least five cases, the recovery was observed in multiple strains, while leastwise in three cases, a single strain was found to be more efficient in recovering a target in the soluble form (T7, T13, and T14). In the other five cases, including the two full-length glycosyltransferases, none of the strains used here was found to recover the target in the soluble form.

To be able to test several different targets in a batch experiment, we missed some optimization procedures that could enhance our recovering rate. For example, the Lemo21 strain can fine-tune the expression level of toxic protein by the titratable regulation of the T7 lysozyme (T7L) expression using L-rhamnose [10,11]. 
pT-GroE, a strain that co-expresses a molecular chaperone to assist the proper protein folding, was found to result in a good recovering rate as well as a good contrast from the target protein to the basal protein expression, making it very easy to follow the target protein being expressed. Similar to pT-GroE, the Arctic Express strain combines low temperature-adapted chaperones Cpn10 and Cpn60, similar to E. coli GroEL and GroES, to result in chaperon assisted and low-temperature protein expression [12]. This strategy was successful in several targets tested here and was also the strain demonstrating a higher recovering rate.

The recovering rate in any structural biology pipeline will always be highly dependent on the targets chosen in the project. In this sense, we have no aim to claim that a given commercial strain is better or worse than each other. Rather than that, we show that it might be worth having a suitable and scalable assay to screen different host strains for the expression of soluble protein in difficult cases. We easily foresee a scenario where proteins that were not recovered in the soluble fraction after a 'standard' protocol can be re-assayed for a 'salvage' pipeline, where different strains are tested for the expression. The experimental cost of this effort includes the transformation of the existing vector in different cell strains and the implementation of a protocol for expression and purification that is scalable and may be implemented in HT format. Protein targets that cannot be recovered in this salvage pipeline are still suitable for changing the construction or even going for eukaryotic cell factories as a host for heterologous expression. In these cases, the experimental costs are slightly higher and involve going back to the construct and primer design, gene cloning, and testing for expression again.

\section{Conclusion}

In conclusion, here we demonstrated that nine out of 16 'difficult' targets could be recovered in the soluble fraction after testing a set of different $E$. coli strains. This easy to implement assay is scalable for a different number of genes and/or strains. We found that the screening may represent an affordable salvage pipeline for the recovery of target proteins which complement a typical pipeline for protein expression and purification in structural biology efforts. 


\section{CRediT Authorship Contribution Statement}

Luana Morão: Conceptualization, Methodology, Validation, Investigation, WritingOriginal draft preparation. Lívia Manzine: Conceptualization, Methodology, Validation, Investigation, Writing- Original draft preparation. Angélica Barra: Investigation, Formal analysis. Lívia Clementino: Investigation, Formal analysis. Raíssa Gutierrez: Investigation, Formal analysis. Carsten Wrenger: Conceptualization, Writing - Review \& Editing, Funding acquisition. Alessandro Nascimento: Conceptualization, Methodology, Writing - Review \& Editing, Supervision, Project administration, Funding acquisition.

\section{Declaration of Competing Interest}

The authors declare that they have no competing financial interests.

\section{Acknowledgments}

The authors thank to the members of the Molecular Biotecnology Group @ IFSC/USP and, in particular, for our technical staff: Maria Auxiliadora Santos, João Possatto and Josimar Sartori. The authors also thank the financial support from the Fundação de Apoio À Pesquisa do Estado de São Paulo (FAPESP) through grants, 2015/26722-8, 2017/03966-4, 2017/24901-8, 2018/21213-6, 2019/20219-3 and 2020/03983-9 and from the Conselho Nacional de Desenvolvimento Científico e Tecnológico (CNPq) through grants 303165/2018-9, 485950/2013-8 and 476606/20101. This study was also financed in part by the Coordenação de Aperfeiçoamento de Pessoal de Nível Superior - Brasil (CAPES) - Finance Code 001. 


\section{References}

[1] C.R. BEDDELL, P.J. GOODFORD, F.E. NORRINGTON, S. WILKINSON, R. WOOTTON, COMPOUNDS DESIGNED TO FIT A SITE OF KNOWN STRUCTURE IN HUMAN HAEMOGLOBIN, Br. J. Pharmacol. 57 (1976) 201209. https://doi.org/10.1111/j.1476-5381.1976.tb07468.x.

[2] G.L. Rosano, E.A. Ceccarelli, Microbial Cell Factories Rare codon content affects the solubility of recombinant proteins in a codon bias-adjusted Escherichia coli strain, (2009). https://doi.org/10.1186/1475-2859-8-41.

[3] J. Kaur, A. Kumar, J. Kaur, Strategies for optimization of heterologous protein expression in E. coli: Roadblocks and reinforcements, Int. J. Biol. Macromol. 106 (2018) 803-822. https://doi.org/10.1016/j.ijbiomac.2017.08.080.

[4] M.T. Sonoda, A.S. Godoy, V.O.A. Pellegrini, M.A.S. Kadowaki, A.S. Nascimento, I. Polikarpov, Structure and dynamics of Trichoderma harzianum Cel7B suggest molecular architecture adaptations required for a wide spectrum of activities on plant cell wall polysaccharides, Biochim. Biophys. Acta - Gen. Subj. 1863 (2019) 1015-1026. https://doi.org/10.1016/j.bbagen.2019.03.013.

[5] C.M. Camilo, I. Polikarpov, High-throughput cloning, expression and purification of glycoside hydrolases using Ligation-Independent Cloning (LIC), Protein Expr. Purif. 99 (2014) 35-42. https://doi.org/10.1016/j.pep.2014.03.008.

[6] W.H. Eschenfeldt, N. Maltseva, L. Stols, M.I. Donnelly, M. Gu, B. Nocek, K. Tan, Y. Kim, A. Joachimiak, Cleavable C-terminal His-tag vectors for structure determination, J. Struct. Funct. Genomics. $11 \quad$ (2010) 31-39. https://doi.org/10.1007/s10969-010-9082-y.

[7] L. Stols, M. Gu, L. Dieckman, R. Raffen, F.R. Collart, M.I. Donnelly, A new vector for high-throughput, ligation-independent cloning encoding a tobacco etch virus protease cleavage site, Protein Expr. Purif. 25 (2002) 8-15. https://doi.org/10.1006/prep.2001.1603.

[8] W.H. Eschenfeldt, S. Lucy, C.S. Millard, A. Joachimiak, I.D. Mark, A family of LIC vectors for high-throughput cloning and purification of proteins., Methods Mol. Biol. 498 (2009) 105-15. https://doi.org/10.1007/978-1-59745-196-3_7. 
[9] F.W. Studier, Protein production by auto-induction in high-density shaking cultures, (2005). https://doi.org/10.1016/j.pep.2005.01.016.

[10] S. Schlegel, J. Löfblom, C. Lee, A. Hjelm, M. Klepsch, M. Strous, D. Drew, D.J. Slotboom, J.W. De Gier, Optimizing membrane protein overexpression in the Escherichia coli strain Lemo21(DE3), J. Mol. Biol. 423 (2012) 648-659. https://doi.org/10.1016/j.jmb.2012.07.019.

[11] S. Schlegel, E. Rujas, A.J. Ytterberg, R.A. Zubarev, J. Luirink, J.W. de Gier, Optimizing heterologous protein production in the periplasm of E. coli by regulating gene expression levels, Microb. Cell Fact. 12 (2013) 24. https://doi.org/10.1186/1475-2859-12-24.

[12] M. Ferrer, T.N. Chernikova, M.M. Yakimov, P.N. Golyshin, K.N. Timmis, Chaperonins govern growth of Escherichia coli at low temperatures, Nat. Biotechnol. 21 (2003) 1267-1267. https://doi.org/10.1038/nbt1103-1266b. 
Table 1. Target genes used for protein expression. The isoelectric point and molecular mass were computed with the ProtParam server. TBP $=$ thiamine biosynthesis pathway. $\mathrm{PBP}=$ pyridoxal 5'-phosphate biosynthesis pathway. GT= glycosyltransferase.

\begin{tabular}{|c|c|c|c|c|c|c|}
\hline Target & Pathway & Organism & $\mathrm{N}_{\text {res }}{ }^{\mathrm{a}}$ & $\mathrm{NCys}^{\mathrm{a}}$ & $\mathbf{p I ^ { \mathbf { a } }}$ & $\mathrm{MW}^{\mathbf{b}}(\mathbf{k D a})$ \\
\hline T1 & TBP & E. faecalis & 276 & 1 & 5.47 & 43.3 \\
\hline T2 & TBP & S. aureus & 276 & 2 & 5.78 & 44.2 \\
\hline T3 & PBP & M. tuberculosis & 299 & 1 & 5.24 & 45.4 \\
\hline T4 & PBP & M. tuberculosis & 199 & 2 & 5.33 & 35.2 \\
\hline T5 & PBP & P. vivax & 302 & 7 & 6.62 & 47.2 \\
\hline T6 & PBP & P. vivax & 219 & 7 & 6.54 & 38.5 \\
\hline T7 & TBP & P. falciparum & 310 & 16 & 6.18 & 49.0 \\
\hline T8 & TBP & P. falciparum & 302 & 11 & 8.88 & 47.9 \\
\hline T9 & TBP & P. falciparum & 400 & 13 & 8.89 & 60.7 \\
\hline T10 & PBP & P. falciparum & 219 & 9 & 6.43 & 38.6 \\
\hline T11 & GT & E. faecalis & 241 & 2 & 6.23 & 40.9 \\
\hline T12 & GT & E. faecalis & 210 & 2 & 6.22 & 37.7 \\
\hline T13 & GT & E. faecalis & 130 & 1 & 4.39 & 28.4 \\
\hline T14 & GT & E. faecalis & 325 & 0 & 9.08 & 51.2 \\
\hline T15 & GT & E. faecalis & 220 & 0 & 5.59 & 39.1 \\
\hline T16 & GT & E. faecalis & 241 & 2 & 6.23 & 26.9 \\
\hline
\end{tabular}

applies to the target sequence, without considering the fusion protein sequence.

${ }^{\mathrm{b}}$ Molecular mass computed with the fusion tag. 
Table 2. Summary of the soluble protein recovery using different $E$. coli strains culture medium. The expression levels, as shown in Figure 1, were quantified on a scale from $(+)$ to $(++++)$. Here, $(-)$ indicates no expression.

\section{E. coli strains}

\begin{tabular}{ccccc}
\hline Target & Arctic & Rosetta Gami & pT-GroE & Lemo 21 \\
\hline T1 & Express & 2 & & \\
\hline T2 & ++ & ++ & ++ & ++ \\
\hline T3 & +++ & + & +++ & + \\
\hline T4 & - & - & - & - \\
\hline T5 & ++ & + & - & ++ \\
\hline T6 & ++++ & ++ & - & ++ \\
\hline T7 & ++ & + & + & - \\
\hline T8 & + & - & + & ++ \\
\hline T9 & - & + & + & - \\
\hline T10 & ++ & ++ & ++ & - \\
\hline T11 & - & - & + & - \\
\hline T12 & ++ & + & + & - \\
\hline T13 & +++ & + & ++ & - \\
\hline T14 & + & - & + & + \\
\hline T15 & +++ & - & + & + \\
\hline T16 & + & + & + & + \\
\hline
\end{tabular}

* The recovery yield levels are ranked from no expression (-) to high yield (++++). 